(a) Universidade do Estado de Minas Gerais, MG, Brasil / joseferjunior@yahoo.com.br

\title{
GESTÃO DO CUSTO INDUSTRIAL EM UMA EMPRESA DO SETOR CALÇADISTA
}

\begin{abstract}
RESUMO
Este artigo objetiva estruturar a formação do custo industrial e do preço de venda em uma empresa do setor de manufatura calçadista, demonstrando as etapas para sua concepção, o porquê de cada etapa e os controles para os parâmetros lançados na construção de ambos os itens. Para tanto, uma pesquisa bibliográfica sobre a teoria vigente foi realizada, salientando a abordagem atual da contabilidade de custos para a gerência e como os cálculos podem ser realizados para se obter tal custo. Visando a aplicação da teoria e da estrutura de custos, apresenta-se um estudo de caso, onde as informações foram coletadas e inseridas para formação e administração dos preços de venda. Como resultado tanto da estruturação dos custos quanto da aplicação, houve a construção da planilha de custo industrial e do preço de venda, além da possibilidade de melhoria contínua nos parâmetros estabelecidos, obtendo, neste caso, cerca de 10\% de ganho no custo industrial.

Palavras-Chave: Formação do custo industrial; Controle de custos; Combinação de custos e gestão de produção

\section{MANAGEMENT OF INDUSTRIAL COST IN THE SHOE MANUFACTURING ENTERPRISE}

\begin{abstract}
This article aims to structure the formation of industrial cost and the selling price in a shoe manufacturing company, demonstrating the steps to its conception, the reason for each step and the controls for the parameters introduced in the construction to both items. To reach this objective, a literature research about the current theory was conducted, emphasizing the current approach of cost accounting to management and how the calculations can be performed to obtain such cost. Aiming on the application of theory and cost structure, we present a case study where the information was collected and entered for training and administration of sales prices. As a result of the cost structure and implementation, there has been the construction of the worksheet of manufacturing cost and the selling price, besides the possibility of continuous improvement in the established parameters, obtaining in this case about $10 \%$ gain in the manufacturing cost.
\end{abstract}

Keywords: training of cost industrial; control of costs; combined costs and management of production 


\section{Introdução}

Evoluir é algo intrínseco ao ser humano, que se adequa a cada novo ambiente que surge com o passar do tempo. Tal característica tem influência em cada organização, por esta ser composta de pessoas, unindo também questões econômicas e conjunturas diversas do ambiente em que está integrada.

Voltando-se para a área fabril, a evolução é notória ao longo das décadas, voltando-se sempre para novas propostas e melhores formas de se empreender neste setor da economia tão competitivo. Porém, muito ainda deve ser feito e instigado para que, no ambiente atual de alta competitividade, as empresas sobrevivam e deem lucros (RAPOSO, 2011).

Visto isto, um dos fatores mais relevantes a serem fomentados dentro das organizações é o de estruturação dos custos e, por consequência, dos preços de vendas de seus produtos. É comum e errôneo que tais decisões estejam atreladas apenas a decisões geradas por conhecimento intrínseco dos gestores, podendo gerar grandes erros que acarretam a falência das empresas. Para evitar possíveis falhas, a contabilidade de custos, atrelada aos conhecimentos de gestão de produção, busca auxiliar os gestores, provendo dados de maior confiabilidade e com possibilidade de visualização de melhorias.

Ratificando esses dizeres, Cohen e Kaimenaki (2011) afirmam que de tais sistemas de contabilidade de custos proveem informações relevantes para a ampliação da compreensão sobre a empresa, oferecendo parâmetros, porém exigindo inserções de dados e obtenção de recursos para mensurações. Contudo, Souza et al. (2006) dissertam que a literatura tanto para estimativas de custos quanto para formação de preços de venda apresenta-se incompleta e esparsa, muito devido ao caráter superficial da maioria dos trabalhos realizados nas empresas, mas também nos estudos puramente teóricos. Betaglin et al. (2013) ilustram a aplicação das mensurações de custos e análise financeira a uma aplicação logística, intercalando as práticas de gestão aqui também fomentadas. Já Walkenbach (2013) estima a utilização cada vez maior de planilhas eletrônicas para a área industrial, com a finalidade de gerir e controlar os parâmetros e recursos das empresas.

$\mathrm{Na}$ indústria de calçados, objeto deste estudo, tais problemas também estão representados. Godinho Filho, Fernandes e Lima (2009), ressaltam que este é um importante setor da economia brasileira tanto pelo seu volume de produção quanto pela sua expressiva participação na pauta de exportações, além da sua capacidade de geração de empregos. Outro ponto a se salientar deste ramo industrial é a busca por melhorias em vista da alta competitividade que o setor atravessa. Isto acarreta, segundo Shingo (1996), Orsini (2010) e Vollmann et al. (2006), investigações por novas formas de atuação, mudanças de processos e de produtos, novos mercados, entre outros quesitos.

Diante das questões levantadas por Godinho Filho, Fernandes e Lima (2009) sobre a contabilidade de custos, a complexidade e as peculiaridades deste setor fabril calçadista como estruturas difusas de produção e produtos diversos - assim como a baixa produção científica voltada para este meio industrial, este trabalho pode ser justificado. Observam-se ainda a grande concorrência e a baixa margem de contribuição por unidade produzida, fomentando novos estudos para esta área.

Diante do apresentado, esta pesquisa tem por objetivo apresentar uma estrutura em forma de planilha para formação do custo industrial e, por consequência, do preço de venda dos produtos na área calçadista, apreciando também um estudo de caso com a implantação de tal estrutura e as melhorias alcançadas com sua utilização.

Como objetivos específicos, têm-se:

- Montar a estrutura de custo industrial para um produto específico;

- Validar teoricamente cada etapa da construção desta estrutura de custos;

- Demonstrar como obter cada dado da planilha;

- Apresentar meios para se controlar os dados descritos no custo do produto e os dados reais do sistema produtivo;

- Comparar os resultados antes e depois da inserção da estrutura em um produto do objeto de estudo.

Dentro deste contexto, a pesquisa se utiliza do método de estudo de caso único, respaldado pela literatura de gestão de custos. Voss, Tsikriktis e Frohlich (2002) afirmam que este método pode ser utilizado para ou elucidar um quadro de investigação de pontos, ou se explicar o porquê e como fenômenos ocorrem em determinado objeto de estudo, ou expor problemas reais com soluções criativas em uma ampla gama de contextos. Lembra-se, entretanto, de acordo com Miguel et al. (2010) e Yin (2005) que tal abordagem, mesmo melhorando a compreensão sobre determinado assunto, não pode ser generalizada para outros ambientes. 
Os passos utilizados para o correto embasamento científico deste estudo de caso se aderem às etapas propostas por Miguel et al. (2010), com a definição da estrutura conceitualteórica, o planejamento do caso, a coleta dos dados com suas análises e a geração deste trabalho.

Dentro da estrutura do texto, há o tópico de Método de pesquisa o qual apresenta, com maior detalhamento, o passo a passo do estudo de caso. Contudo, anteriormente a ele, aborda-se uma revisão sobre as terminologias utilizadas no contexto de gestão de custos e definições para o bom prosseguimento da pesquisa. Posteriormente ao método, apresenta-se o desenvolvimento do trabalho, com as características do objeto de estudo e a ênfase no como e o no porque da estrutura de custos e preços de vendas. Demonstram-se, após isto, os controles de cada etapa abordada na estrutura de custos, enfatizando as melhorias que podem ser obtidas com tais controles e com a gestão da produção agregada aos custos industriais. Por fim, dão-se as conclusões e as especificidades desta pesquisa.

\section{Revisão Teórica}

\subsection{Gestão da Produção}

Todo tipo de produção pode ser definido como uma rede de processos e operações. A transformação de matéria-prima em produtos acabados é dada como processo, já os meios disto ocorrer é tido como operação. Uma análise separada do fluxo de produto (processo) e fluxo de trabalho (operação) se faz necessária com vistas a melhorias no processo de produção. Contudo, ressalta-se que tais melhorias devem considerar o processo como um todo e não cada operação individualmente, já que se considerarmos apenas estas os resultados obtidos poderão apresentar redução de eficiência global. (SHINGO, 1996).

Analisando estes conceitos em um ambiente de extrema competição, nota-se mais do que nunca que os cinco objetivos estratégicos da produção propostos por Slack, Chambers e Johnston (2009) - custo, qualidade, flexibilidade, confiabilidade e velocidade tornam-se essenciais para a sobrevivência e crescimento das organizações. Contudo, mesmo diante disto e com diversas técnicas de gestão já apresentadas na literatura, há empresas que ainda adotam políticas baseadas no knowhow, ou seja, no conhecimento de determinados colaboradores, para tomar decisões. A consequência disto é que as decisões tomadas podem ser apenas a ponta do iceberg e todo o resto pode não ser observado pelos gestores (CLEGG; HARDY; NORD, 1998).

Dentro de todo o escopo da administração da produção, entretanto, há pontos dos mais diversos para se melhorar e buscar padronização e sistematização, convergindo dados e informações reais em busca de soluções ideais para os fatores de sucesso do empreendimento. Técnicas como cronoanálise, arranjos físicos de processos, balanceamento de linhas, limpeza e organização, eliminação de desperdícios, dentre tantas outras, podem vir a ser empregadas para auxiliar a gestão como um todo dos sistemas produtivos.

Sistemas mais complexos de administração da produção também podem vir a ser utilizados, buscando favorecer a empresa como um todo, sendo os mais comuns: Just in time (JIT); Optimized Production Technology (OPT); Material Requirements Planning (MRP); Manufacturing Resources Planning (MRP II); e Enterprise Resource Planning (ERP). Cada qual conserva características próprias e tende a propiciar melhores soluções para determinados tipos de processos (LAURINDO; MESQUITA, 2000; SLACK; CHAMBERS; JOHNSTON, 2009).

Contudo, de nada adianta sistemas ou técnicas de gestão produtiva se as mesmas não são implantadas ou o são de forma errônea. A falta de acessibilidade ou usabilidade dos funcionários às técnicas e a falta de intercambialidade delas com o meio produtivo, também são erros que devem ser evitados nas empresas.

\subsection{Gestão dos Custos}

\subsubsection{Visão Geral}

Um dos pontos utilizados em conjunto com a gestão produtiva diz respeito ao controle dos custos de produção e, por consequência, dos preços de vendas dos produtos. Mesmo normalmente separados em estruturas hierárquicas dentro das empresas, ambos podem ter uma coexistência benéfica para as organizações, em vista de propiciarem melhorias e tornar a empresa mais competitiva no mercado.

Contudo, Souza et al. (2006) alertam que as empresas têm dificuldades em estabelecer preços e custos ou por não serem capazes de calcular, ou por delegarem tal função apenas ao mercado. Porém, com uma metodologia de formação do custo industrial e do preço de 
venda, melhores informações podem ser dadas aos gestores, criando um sistema passível de controle e que pode ser tornar uma vertente de melhorias.

Sobre os sistemas de custos, Cohen e Kaimenaki (2011) dissertam que os mesmos devem prover informações relevantes, tendo flexibilidade e contribuindo para os controles operacionais e estratégicos. Sua estrutura é caracterizada pelo nível de detalhamento das informações, pela capacidade de se desagregar os custos de acordo com seus comportamentos e pela frequência com que os dados são coletados e lançados. Todavia, Cooper e Kaplan (1988) enfatizam que, pela alta distribuição das funções e pelos novos métodos produtivos, há uma maior complexidade na composição dos custos, tornando-os, por muitas vezes, errôneos.

Diante de tais dificuldades e levando em consideração a interdependência entre os produtos e o mercado, há a necessidade de se estabelecer custos estimados antes da execução em si. Para tanto, utilizam-se abordagens encontradas na literatura ou criam-se meios para averiguações e tabulações dos valores dentro da empresa.

Shehab e Abdalla (2001) expressam que esta estimativa de custos pode ser efetuada por diversas técnicas, como variações de modelos já executados, generalizações de produtos, parametrizações de processos, entre outros. Já Souza et al. (2006) enfatizam que dentre os meios para formação dos preços, três se sobressaem, sendo baseados nos custos de produção, na concorrência, ou no valor percebido pelo consumidor. Neste trabalho, contudo, será analisado apenas o modelo baseado nos custos de produção, observando o fluxo de valor o qual é o conjunto de todas as atividades que ocorrem desde a obtenção da matéria-prima até a entrega ao consumidor final.

\subsubsection{Definições e Classificação de custos}

Resumidamente, para entendimento das definições de custos, podem ser citados os seguintes itens e seus significados mais aceitos na literatura (COLMANETTI, 2001; MARTINS, 2010; SILVA, 2002):

- Gasto: aquilo utilizado para obtenção de produtos e serviços;

- Investimento: utilizado para obtenção de um benefício futuro, registrado no ativo da empresa;

- Custo: gasto utilizado na produção de bens ou serviços para obtenção de lucros - podem ser divididos de acordo com a dependência da produção ou sobre a disposição perante os produtos:

o Custos variáveis: dependem do volume de produção;

o Custos fixos: independem do volume de produção;

o Custos semivariáveis: tem uma parcela de custos fixos e outra de variáveis;

o Custos semifixos: permanecem constantes em intervalos de tempos, alterando ao subir ou descer de classe de gastos;

o Custos diretos: aplicados diretamente sobre o produto ou serviço;

o Custos indiretos: não se identificam diretamente sobre o produto, necessitando de uma forma de rateio para serem alocados.

- Despesas: gasto não identificável diretamente no processo de transformação ou geração de bens e serviços;

- Desembolso: pagamento resultante da aquisição do bem ou serviço;

- Perda: consumo de forma anormal ou involuntária de determinado recurso;

- Margem de contribuição: diferença entre o preço de venda e o custo total de cada produto, ou seja, o que cada unidade efetivamente traz à empresa.

Nem todos na literatura convergem para como e quando utilizar determinado tipo de custo ou despesa. $\mathrm{O}$ que se apresenta convergente entre todos é que, diante de todas as definições, a mais complexa é de rateio dos custos indiretos da produção. Por tal motivo, no desenvolvimento desta pesquisa, o cuidado maior será dado na explanação de tal tipo de valores.

\subsubsection{Método ABC de Custeio}

Com a finalidade de se mensurar os custos internos, vários métodos foram criados e são utilizados atualmente. Os mais comuns tipos de rateio dos custos indiretos são: proporcionalidade de horas-máquina, mão de obra direta, matéria-prima ou custo direto total; absorção, somando todos os custos e dividindo pela previsão de vendas ou pedidos em carteira; custeio variável, o qual aloca os custos de acordo com a margem de contribuição; ABC (Custeio baseado em atividade), o qual identifica as atividades relevantes e os custos que incidem sobre as mesmas (COLMANETTI, 2001; COOPER; KAPLAN, 1988; MARTINS, 2010; 
SILVA, 2002).

Focando um pouco mais no custeio ABC, Cooper e Kaplan (1988) desenvolveram a ideia de se mensurar e alocar os custos de produção por processos e não mais por departamentos, determinando passos que vão desde a verificação da acurácia dos dados sobre mão de obra e insumos, até recursos específicos de cada produto ou processo. Lee e Bowhill (1997) afirmam também que o manejo correto permite direcionar os custos apropriadamente, alcançando o desempenho desejado, porém lembram que tal método é oneroso e de difícil manutenção.

Contudo, de nada adianta formar o custo se o mesmo não gerar informações para controle no dia a dia. Martins (2010) ressalta que se deve conhecer a realidade para compará-la com os parâmetros pré-estabelecidos. Slack, Chambers e Johnston (2009) ditam que controles sobre o desempenho padrão dos funcionários e processos geram os dados reais do sistema e estabelecem que haja o comprometimento dos mesmos para o enriquecimento do fluxo de valor. Por fim, Clegg, Hardy e Nord (1998) citam que, por meio do conhecimento interno, as organizações ganham experiência e se autodesenvolvem.

Gerando e gerindo tais informações, é comum que as empresas adotem o chamado custo padrão, o qual se apresenta como uma predeterminação prevista do que provavelmente ocorrerá no meio produtivo. Este custo ressalta, em valores monetários, quanto cada setor, processo, atividade ou departamento (dependendo do tipo de rateio efetuado) influencia no custo final do produto, oferecendo parâmetros aos gestores para controles de produção e simulações de cenários (COLMANETTI, 2001; MARTINS, 2010).

Martins (2010) ainda separa o custo padrão em dois tipos: o ideal (valor obtido com a utilização das melhores matérias-primas com a mão de obra mais eficiente e com capacidade total da empresa em uso) e o corrente (inclui deficiências e problemas do setor produtivo e administrativo). O mesmo autor ainda afirma que o custo padrão ideal é uma meta a ser sempre buscada como o foco do empreendimento, enquanto o corrente torna-se o padrão aceitável para as rotinas e deve ser sempre analisado e alterado rumo ao ideal.

Para esta evolução do corrente para o ideal, cabe aos líderes buscar o desenvolvimento contínuo, vislumbrando melhorias nos processos produtivos, na gestão da qualidade, na manutenção produtiva, nos fluxos pela cadeia de suprimentos, entre outros. A chave, aqui, é moldar o ambiente administrativo e de produção, de forma a atingir os objetivos propostos e evoluir ao longo do tempo (RAPOSO, 2011; SLACK; CHAMBERS; JOHNSTON, 2009; VOLLMANN et al., 2006; TORRES JÚNIOR; MIYAKE, 2011).

Por fim, em seu estudo, Cohen e Kaimenaki (2011) apresentam a conclusão de que os gestores reconhecem a importância de receber dados e informações de custos durante o processo para tomar decisões corretas. Também enfatizam que se deve buscar melhorias nos setores e atividades da empresa para sempre reduzir os custos ou aumentar a margem de contribuição.

\subsection{Formação da Planilha de Dados}

As planilhas eletrônicas são ferramentas extremamente funcionais, tendo por característica moldar-se de acordo com o objetivo de seu usuário. Tais estruturas podem ser reutilizadas ou arquivadas, tantas vezes quanto for necessário.

Definem-se as mesmas como uma grande matriz, onde as colunas são designadas por letras e as linhas por números. A intersecção destas formam as células que podem conter números, letras ou fórmulas e estarem relacionadas a outras células. Esta possibilidade de interrelação de dados é que condiciona poder às planilhas (MASSING, 2006).

Suas aplicações são diversas, tais como: preparação de orçamentos, modelagem financeira, geração de papel de trabalho, preparação de orçamentos, análise de custo benefício, determinação de retornos sobre investimentos, modelagem matemática, análise de dados científicos e de engenharia, projeção de mercado, avaliação de viabilidade de investimentos, fusões, aquisições, entre outras aplicações administrativas ou mesmo de contabilidade (CORREIA NETO, 2007).

Hoje, o software mais utilizado para execução destas é o Microsoft Excel®. Algumas características básicas do programa são, de acordo com Walkenbach (2013):

- Transferência de dados: possibilita importar dados de outras planilhas e outros programas;

- Automatização de tarefas complexas: executa problemas complicados com um simples clique do mouse por meio de macros;

- Suplementos de análise estatística, financeira e otimização: possibilita criar 
orçamentos, analisar resultados de pesquisas, realizar análise financeira e solucionar modelos de otimização.

Deste modo, por possuir essa gama de aplicações, todos os dias milhões de pessoas utilizam programas de planilha para a criação de modelos de problemas empresariais e pessoais. Em função destas características, a estrutura para gestão de custos objetivada por este trabalho, utilizou-se de estruturas em formato estratificado, facilitando as alterações por parte do gestor e a inclusão de dados pelos usuários.

\section{Método de Pesquisa}

Dentre os métodos de pesquisas apresentados por Yin (2005) e Miguel et al. (2010) (pesquisa bibliográfica, estudo de caso, levantamento/survey, experimento, modelagem e simulação e pesquisa-ação), o que melhor se adéqua a esta pesquisa é o Estudo de Caso, a qual explora uma estrutura criada em um objeto de estudo e observa as melhorias ocorridas em função da mesma.

Confirmando esta escolha, Voss, Tsikriktsis e Frohlich (2002) afirmam que o Estudo de Caso pode ser estabelecido por um histórico de dados ou por um fenômeno corrente desenhado por múltiplas evidências, tendo caráter exploratório, tendendo a refinar uma teoria já existente.

As etapas a serem seguidas para a condução deste estudo de caso são apresentadas na Figura 1, e explanadas uma a uma neste tópico, apresentando como foi executado o desenvolvimento desta pesquisa.

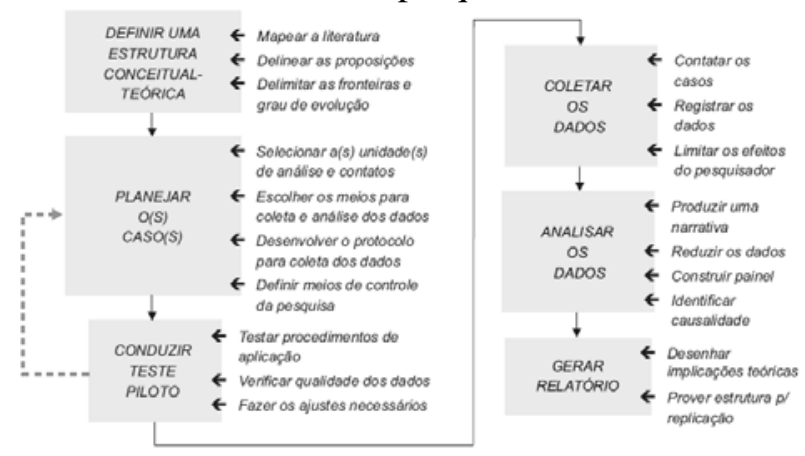

Figura 1 - Condução do Estudo de Caso

Fonte: MIGUEL et al., 2010, p. 135

A primeira etapa teve por objetivos mapear a literatura, delinear as proposições e delimitar as fronteiras. Esta já foi executada nos tópicos anteriores deste trabalho, demonstrando as definições para: gestão da produção, gestão de custos e planilhas eletrônicas.

A segunda etapa descrita como planejamento do caso inicia-se no Tópico 4, apresentando o objeto de estudo. Este local apresenta toda a estrutura de gestão de custos e de controles dos parâmetros da planilha eletrônica executada nesta pesquisa.

Por meio desta estrutura e destes parâmetros, o passo de Coleta de dados inicia-se, montando o custo industrial de um produto e, em sequência, seu preço de venda. As informações são aferidas por meio contábil (impostos e encargos), do setor de compras (preço de compra de produtos), do setor de recursos humanos (salário dos colaboradores) e do setor de engenharia de processos (custos de manutenção, setorização da empresa, entre outros). Também nesta etapa, melhorias executadas na organização são apresentadas com a finalidade de demonstrar as consequências das mesmas no custo dos produtos, atrelando assim, ambos os contextos (gestão de produção e gestão de custos).

A terceira etapa, teste piloto, foi descartada por se tratar de um estudo de caso único, tendo assim, conclusões únicas para este objeto de estudo. Contudo, a ideia central e a estrutura de gestão de custos, conforme apresentado no planejamento do caso, pode ser adequada para outras indústrias do mesmo ramo, em vista da particularidade de planilhas eletrônicas serem flexíveis a alterações.

Já na quinta etapa de análise dos dados, as informações e dados são discutidos, analisados e possibilitaram a aplicação da planilha no caso estudado. Tal item se apresenta no Tópico 5 e é explanado em cima da tabulação final de todos os dados da gestão de custos.

Por fim, o último tópico proposto por Miguel (2007) - Geração do relatório - é apresentado como um todo no texto, explanando todas as considerações e permitindo a replicação desta pesquisa em outros meios ou ramos industriais.

\section{Desenvolvimento da Pesquisa}

\subsection{Planejamento do Caso - Apresentação da empresa}

Como o primeiro passo descrito por Miguel (2007) já foi alocado no Tópico 2 deste texto, parte-se para o segundo passo que é o Planejamento do Caso. Sobre a escolha do objeto de estudo, este foi apontado devido à intensa competição e baixas margens de contribuição do ambiente calçadista, o qual é uma das principais atividades econômicas da região de Franca, interior do estado de São Paulo. Sobre a empresa, a mesma possui cerca 80 funcionários, com 15 produtos em seu mix. 
Suas vendas são voltadas para distribuidores, lojas comerciais e para outras empresas, com um giro de capital na faixa de 400 mil reais por mês, considerando compras, vendas, investimentos, impostos, entre outros.

Porém, conforme já dito, observam-se empresas que, mesmo neste ambiente competitivo, trabalham apenas com o conhecimento intrínseco de seus colaboradores, não planejando nem se atualizando com as evoluções dos ambientes de negócio. No caso do objeto de estudo, tal fato demonstrou-se extremamente prejudicial à organização, visto que, em seis meses de funcionamento, o prejuízo chegou ao patamar do investimento inicial do estabelecimento, exigindo a duplicação, portanto, da injeção de capital prevista pelos proprietários.

A fim de se organizar o ambiente, um dos primeiros trabalhos a serem efetuados foi o de averiguação dos preços de vendas de seus produtos. Para tanto, decidiu-se refazer toda a estratificação dos gastos para cada produto executado. Pretende-se, com esta estrutura, chegar ao preço de venda e conseguir controlar o custo real tendo uma base mais sólida do que o know-how dos gestores.

Nos subtópicos a seguir, desdobra-se o como e o porquê de cada etapa desta compilação de dados em forma de planilha. A validação de cada etapa é dada por meio de trabalhos da literatura pertinente, demonstrando também o raciocínio dos pesquisadores ao elaborar tal estrutura.

\subsection{Planejamento do caso - Estratificação de Custos}

\subsubsection{Matérias-primas e insumos}

Colmanetti (2001) disserta que os dois elementos básicos para formação dos custos são a mão de obra e a matéria-prima. Silva (2002) aponta também que deve haver a separação entre aqueles que são diretamente associados ao produto daqueles que não o são. Iniciando pelos materiais, diz-se que todos aqueles que são os passíveis de medição direta perante uma unidade de um produto, são considerados matériasprimas diretas. Os demais, de utilização comum ou de difícil separação por unidade produzida, são considerados como matérias-primas indiretas (MARTINS, 2010).

Este trabalho, provido de informações documentais do objeto de estudo, simplifica tais termos em: "matérias-primas", para os materiais diretamente alocados; e "insumos", para os indiretamente alocados. Para os materiais dos setores de apoio, outro campo de controle será desenvolvido.

Efetuando esta separação, especificamente para calçados (ramo de atividade do objeto de estudo), nota-se que materiais como couros, forros, peças de acabamento, solados, entre outros, os quais têm preços de compra considerados altos e consumos controlados, apresentam-se como diretos. Já colas e linhas, principalmente, que são de difícil mensuração por unidade, apresentam-se como indiretos.

Cada matéria-prima é lançada, uma a uma, no campo específico, descrevendo-a e inserindo a previsão de consumo por produto e seu preço de compra. A previsão de consumo é dada inicialmente pelo setor de desenvolvimento de produtos, o qual mede a área das peças e insere o valor na planilha. Posteriormente, por controles demonstrados no Tópico 4.3.1, os valores podem vir a ser alterados, de acordo com a experiência produtiva. A somatória total da multiplicação entre a quantidade gasta e o preço de compra de cada item fornece o custo deste quesito no produto acabado. A Equação 1 demonstra tal formulação.

$$
C_{m p}=\sum P_{n} \times P C_{n}
$$

Onde:

Cmp - Custo total de matérias-primas;

$n$-número de itens de matérias-primas;

$P n$ - quantidade gasta por matéria-prima;

PCn - preço de compra por matéria-prima.

Lembra-se aqui que o preço de compra dos produtos deve seguir a política da empresa ou em lançar pelo último preço comprado, ou pelo sistema contábil PEPS ou UEPS, ou pelos preços firmados em contrato com os fornecedores, deduzidos os impostos previstos por lei, assim como apresentado por Martins (2010).

Para os insumos, o cálculo apresenta-se mais complexo, pois o controle é dado por períodos ou por lotes e não por unidades. A equação 2 apresenta o modelo de cálculo do custo total de insumos (CI), na abordagem de rateio por absorção, onde se somam todos os insumos gastos no período ou lote (I) multiplicando-os pelos preços de compra $\left(\mathrm{PC}_{n}\right)$ e dividindo-os pela quantidade produzida $(\mathrm{Q})$.

$$
C I=\frac{\sum I_{n} \times P C_{n}}{Q}
$$

Contudo, como o preço de venda deve ser estipulado antes da produção, executa-se uma previsão sobre o total produzido de calçados $(\mathrm{Q})$, estimando normalmente por histórico qual o valor a ser gasto destes insumos (SHEHAB; ABDALLA, 2001; SOUZA et al., 2006). 


\subsubsection{Mão de obra}

$\mathrm{O}$ segundo fator a ser analisado e computado é o de mão de obra. A formatação mais usual de distribuição dos custos referentes aos colaboradores é por centros de custos, os quais são separações por departamentos ou setores da empresa (MARTINS, 2010; SHEHAB e ABDALLA, 2001).

Como cada empresa possui características próprias vindas de suas estratégias de produção, cada modelo de separação dos custos de mão de obra acaba por ser único (LEE; BOWHILL, 1997). Outro fator que gera complexidade neste quesito é o desenvolvimento de novos tipos de layouts produtivos que tornam os funcionários multifuncionais em vários produtos (COOPER; KAPLAN, 1988). Por fim, existem as necessidades da empresa, atreladas à sua estratégia, a qual tende a buscar o mínimo de custos em todos os setores, incluindo os administrativos, tornando o controle de operações e atividades difícil de ser mensurado por todos os envolvidos terem multitarefas diárias (VOLLMANN et al., 2006).

Neste estudo, por se tratar de um setor que mantém forte a política departamental, a separação dos custos de mão de obra $\left(\mathrm{C}_{\mathrm{mo}}\right)$ pelo método de centros de custo acaba por ser simplificada em termos de macro estratégia. Com isto, a solução é dada pela soma dos salários $\left(F_{m}\right)$ com encargos e impostos governamentais sobre os salários dos funcionários (tx) separando-os setor a setor da empresa (k). A equação 3 demonstra tal formulação.

$$
C_{m o}=\sum_{k} \sum_{j=1}^{m} F_{m} \times t x
$$

Contudo, nos setores produtivos, a separação, conforme já dito, complica-se, pois um funcionário pode trabalhar em mais de um produto. A estratégia utilizada para esta gestão é a de ratear, pelo tempo de processamento, quanto de cada funcionário ou grupo de funcionários ficará estimando no custo unitário, desenvolvendo, assim, uma variação da abordagem de custeio ABC.

A estimativa do tempo de processamento pode ser feita por histórico de produção, por semelhança de operações ou por testes no produto piloto, buscando apresentar dados os mais precisos possíveis para com o real. Outra forma, utilizada principalmente para atividades de difícil mensuração de tempos, é a de ratear os salários pela produção total, como no custeio por absorção. Porém, aqui corre-se o risco de se atribuir mais ou menos custos do que o real para um produto.

O controle do rateio da mão de obra e determinação do valor padrão apresentar-se-á no Tópico 4.3.2 deste artigo, auxiliando no desenvolvimento da planilha final.

\subsubsection{Investimentos e manutenção}

Também chamados de custos fixos $\left(\mathrm{C}_{\mathrm{f}}\right)$ ou despesas gerais na literatura, estes custos são os necessários para o funcionamento do empreendimento, como estoque de peças de manutenção de maquinário, materiais diversos para limpeza ou escritório, entre outros. Também aqui, podem-se alocar recursos proporcionais para futuros investimentos ou pagamentos financeiros de juros ou apólices (COLMANETTI, 2001; MARTINS, 2010).

Para isto, tantos campos quanto necessários podem ser desenvolvidos, descrevendo o que será contemplado em cada um deles. Por exemplo, separando materiais de escritório, de limpeza e de manutenção, pode-se, por histórico, estimar os gastos com cada um e ratear pelo total a ser produzido no período ou no lote. Outro exemplo, a questão de investimentos, pode ser colocado como um percentual sobre os custos totais, como se para cada produto executado, este auxiliasse na melhoria de toda a empresa.

Conforme se observa, ambos os lados do cálculo (quantidade gasta com materiais e quantidade produzida) podem ser estimados, o que traz em pauta a obrigação de controles para averiguação dos dados, permitindo a confirmação se os dados tabulados são reais perante o dia a dia da empresa. No Tópico 4.3.3 deste trabalho, tal método de controle será discutido.

\subsubsection{Impostos, encargos e lucro}

Com os três itens anteriores (materiais, mão de obra e investimentos/manutenção) finaliza-se o chamado custo industrial, somando os resultados de cada um. Agora, para o preço de venda, deve-se também contar os impostos e encargos referentes à produção do item. Cada região e cada setor industrial tende a ter suas tabelas de reclusão de capital para pagamento de tais tributos, sendo que órgãos governamentais e sindicais também auxiliam na composição dos mesmos.

A mesma estratégia adotada no campo tabulado como investimentos pode vir a ser utilizada aqui, lançando percentuais sobre 
imposto de renda, PIS/Confins, ICMS, entre outros. A questão do pró-labore, do lucro por unidade e de comissões sobre vendas também podem aderir ao mesmo conceito, lançando proporções sobre o custo industrial total e concluindo este tópico.

\subsubsection{Preço de venda}

Sobre o preço, Souza et al. (2006) dita que o mesmo é a soma dos valores que os consumidores trocam pelo benefício de possuírem ou usarem um produto ou serviço, sustentando a estratégia de posicionamento da firma, atingindo os objetivos financeiros e ajustando à oferta de mercado. Contudo, como este trabalho trata apenas da formação do preço baseado nos custos de produção, conforme já dito, apresentou-se passo a passo os itens a serem incluídos na estratificação para formação do preço de venda de determinado produto, tomando por base o objeto de estudo na manufatura calçadista.

Nesta linha de raciocínio, o preço de venda é calculado pela soma dos custos incorridos para produção do bem ou serviço dividido pelo complemento dos impostos, encargos e lucro, ou seja, a divisão entre o custo industrial e o Mark-up (SOUZA et al., 2006), conforme demonstrado na Equação 4.

$$
P V=\frac{\left(C_{m p}+C I+C_{m o}+C_{f}\right)}{1-\sum \text { imp; enc; luc }}
$$

Onde, $\sum$ imp; enc; luc - somatória dos impostos, encargos e lucro do produto (tópico 2.4 do texto).

\subsubsection{Planilha final}

Diante de todos os dados coletados e moldados na estrutura descrita durante o desenvolvimento da pesquisa e validados pelos autores citados, apresenta-se a Tabela 1 , a qual demonstra a máscara da planilha do formato ao qual um dos produtos do objeto de estudo terá seu custo executado.

\subsection{Planejamento do Caso - Apresentação dos controles}

Conforme nota-se, a criação de uma planilha que convirja os dados sobre os custos de produção e os preços de venda não é um início nem um fim na estratégia e melhoria do setor produtivo. Dados devem ser coletados e mantidos em históricos para criação da estrutura estratificada e outros devem ser controlados para manutenção da mesma e averiguação das situações ideais para as reais. Contudo,
Nazareno, Rentes e Silva (2001) observam que gastar tempo ou recursos em controles ou atividades que não gerem frutos, não trará efeito algum e ainda desgastará a equipe de apoio.

Tabela 1 - Máscara p/ Planilha de Custos e Preço de Venda

\begin{tabular}{|c|c|c|c|c|c|}
\hline \multicolumn{6}{|c|}{ Custo industrial } \\
\hline Modelo & $\overline{\mathrm{XXXX}}$ & & Cliente & $\overline{\mathrm{XX}}$ & $\overline{\mathrm{XX}}$ \\
\hline \multicolumn{6}{|c|}{ Matérias-Primas } \\
\hline Cód & Descrição & Unid & $\begin{array}{c}\text { Consumo } \\
\text { unitário }\end{array}$ & \begin{tabular}{|c|} 
Preço \\
de \\
compra \\
\end{tabular} & $\begin{array}{c}\text { Custo } \\
\text { unitário }\end{array}$ \\
\hline & & & & & $\mathrm{R} \$-$ \\
\hline & \multicolumn{4}{|c|}{ Custo total de matérias-primas } & R\$ - \\
\hline \multicolumn{6}{|c|}{ Insumos } \\
\hline Cód & Descrição & Unid & $\begin{array}{l}\text { Consumo } \\
\text { período }\end{array}$ & \begin{tabular}{|c|} 
Preço \\
de \\
compra \\
\end{tabular} & \\
\hline & & \multicolumn{3}{|c|}{ Quantidade pares produzidos } & \\
\hline & & \multicolumn{3}{|c|}{ Custo total de insumos } & \\
\hline \multicolumn{2}{|c|}{ Mão de obra } & & \multicolumn{2}{|c|}{$\begin{array}{l}\text { Investimentos } \\
\text { Manutenção }\end{array}$} & \\
\hline & 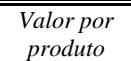 & & Descrição & Total & \\
\hline \multicolumn{2}{|l|}{ Administração } & & Desp. Fixas & & \\
\hline \multicolumn{2}{|l|}{ Produção } & & Frete & & \\
\hline \multirow{2}{*}{\multicolumn{2}{|c|}{$\begin{array}{c}\text { Expedição } \\
\text { P\&D }\end{array}$}} & & Investimento & & \\
\hline & & & Manutenção & & \\
\hline \multicolumn{2}{|l|}{ Outros } & & Outros & & \\
\hline Custo total & $\mathbf{R} \mathbf{S -}$ & & Custo Total & $\mathbf{R} \$-$ & \\
\hline \multicolumn{3}{|c|}{ Total do Custo industrial } & R\$ - & & \\
\hline \multicolumn{6}{|c|}{ Preço de Venda } \\
\hline \multicolumn{2}{|c|}{ Mark-up } & & \multicolumn{2}{|c|}{ Preço de venda } & \\
\hline Setor & $\begin{array}{c}\text { Percentual } \\
\text { por produto }\end{array}$ & & \multirow[t]{10}{*}{ R\$ - } & & \\
\hline ICMS & & & & & \\
\hline PIS & & & & & \\
\hline ISS & & & & & \\
\hline IR & & & & & \\
\hline Comissão & & & & & \\
\hline \multicolumn{2}{|l|}{ Juros e Taxas } & & & & \\
\hline \multicolumn{2}{|l|}{ Lucro } & & & & \\
\hline Total & $0,00 \%$ & & & & \\
\hline MARKUP & $100,00 \%$ & & & & \\
\hline
\end{tabular}

Fonte: Elaborado pelo autor

Portanto, devem-se controlar apenas os dados que interferem no custo, criando relatórios para análise dos desempenhos da empresa. É função destes controles a observação das variações que ocorrem nos processos e a adequação do planejado de acordo com os dados obtidos por eles, visando uma maior eficiência sem comprometer a eficácia dos processos (SLACK; CHAMBERS; JOHNSTON, 2009; TORRES JÚNIOR; MIYAKE, 2011).

Para tanto, a utilização do custo padrão para determinação dos parâmetros de meta a serem controlados vem a ser apropriada. Esta padronização permite direcionar os gestores para escolhas corretas e reforçam a ideia de revisões periódicas do sistema para averiguação se os dados lançados na planilha de custo industrial estão em conformidade com o praticado dentro de todos os setores da empresa (LEE; BOWHILL, 1997).

Com isto, cada subtópico da formação do 
custo industrial e do preço de venda já descritos no texto deve vir a ser conferido e controlado, averiguando se os objetivos são atingidos e se há espaço para melhoria nos parâmetros da estrutura geral.

\subsubsection{Controle das matérias-primas e insumos}

Um dos mais básicos controles é o de matérias-primas, pois, como são materiais utilizados diretamente nos produtos, o controle é feito pela mensuração do quanto se gastou para cada produto (MARTINS, 2010).

A Tabela 2 apresenta um modelo de controle para estes materiais diretos, onde para cada item descrito na Tabela 1 , há a previsão de consumo para o lote a ser produzido (dada pelo setor de desenvolvimento de produtos), o consumo real (medido durante a execução do lote) e o percentual de variação, sendo positivo em caso de se consumir menos do que o previsto e negativo, em caso de consumir mais. Tais variações ocorrem devido a fatores diversos de produção, como melhor ou pior aproveitamento de materiais, perdas ou refugos, setup de maquinário, entre outros.

Com este dado percentual, torna-se possível alterar, diante de um histórico, os dados computados na planilha de formação de custos. Simplificando, caso o dado inicialmente alocado não esteja condizendo com a experiência produtiva, o mesmo pode ser modificado para cima ou para baixo de acordo com os percentuais apontados neste controle.

Tabela 2 - Controle de matérias-primas por lote

\begin{tabular}{llllll}
\hline Modelo & $8585 / 9-500$ & Cliente & \multicolumn{2}{l}{ XXXX } \\
\hline & & Lote & & 30 & Pares \\
Cód. & Descrição & Unid. & Previsão & Real & $\%$ \\
\hline 100.000 .001 & Raspa Relax S1 18/20 mm & $\mathrm{m}^{2}$ & $\mathbf{5 , 7 7 5}$ & 5,680 & 1,65 \\
\hline 100.000 .003 & Napa Relax 10/12 mm & $\mathrm{m}^{2}$ & $\mathbf{1 , 3 8 6}$ & 1,400 & $-1,01$ \\
\hline Fonte: Elaborado pelo autor & & & &
\end{tabular}

Fonte: Elaborado pelo autor

O controle nos preços de compra dos materiais também é de importância considerável, visto que, alterações nos mesmos sem a simultaneidade no custo industrial trazem erros nos cálculos finais, tanto de perdas quanto de ganhos. É comum, ao fim de um período, todos os valores de aquisição serem repassados aos setores para monitoramento e atualização da estrutura de custos montada.

Já com relação aos insumos, o controle é feito para se confirmar se o valor lançado no custo industrial (também apresentado pelo setor de desenvolvimento de produtos) converge com o valor dado em uma experiência real, adequando o histórico e atualizando o mesmo, assim como explicado para os materiais diretos.
Como exemplificação, a Tabela 3 mostra os produtos a serem utilizados e tabula-se o real, conforme os recursos gastos no período de mensuração. A relação é baseada no total previsto de produção, o qual, para o período estudado era de 16000 pares por mês, mas com dados reais do histórico da empresa de produção de 15000 pares em média nos três últimos meses de funcionamento. Nota-se que, neste exemplo, utilizando os dados ditados neste tópico, o valor final resultou em um prejuízo neste quesito, cabendo aos gestores a decisão, diante do histórico, de aumentar ou não o valor do custo para os insumos.

\begin{tabular}{llllll}
\multicolumn{6}{l}{ Tabela 3 - Controle de insumos por período } \\
\hline Cód. & Descrição & Unid. $\begin{array}{l}\text { Preço de } \\
\text { compra }\end{array}$ & $\begin{array}{l}\text { Previsto } \\
(\mathrm{kg})\end{array}$ & $\begin{array}{l}\text { Real } \\
(\mathrm{kg})\end{array}$ \\
\hline 125.001 .030 & Linha 30 preta & $\mathrm{kg}$ & $\mathrm{R} \$ 35,25$ & $\mathbf{3 0}$ & 25 \\
\hline 125.001 .040 & Linha 40 preta & $\mathrm{kg}$ & $\mathrm{R} \$ 35,25$ & $\mathbf{1 5}$ & 17 \\
\hline 125.005 .040 & Linha 40 branca & $\mathrm{kg}$ & $\mathrm{R} \$ 35,25$ & $\mathbf{2 0}$ & 23 \\
\hline 120.001 .001 & Cola SWT Amazonas & $\mathrm{kg}$ & $\mathrm{R} \$ 75,00$ & $\mathbf{4}$ & 5 \\
\hline \multicolumn{7}{c}{ Quantidade de pares produzidos } & 16000 & 15000 \\
\hline \multicolumn{7}{l}{ Custo total de insumos } & $\mathbf{R} \mathbf{0 , 1 6}$ & $\mathbf{R} \mathbf{0 , 1 8}$ \\
\hline
\end{tabular}

Fonte: Elaborado pelo autor

\subsubsection{Controle da mão de obra}

Um dos controles mais complexos é o de mão de obra, devido à interdependência de cada centro de custo para com a produção de todos os modelos e para com eles mesmos. Seu controle pode ser feito integrando duas tabulações: a primeira diz respeito ao balanceamento da linha ou célula produtiva para o número de funcionários que atuam diretamente no processo; a segunda diz respeito ao lançamento dos que atuam indiretamente. A resultante disto pode ser vista nos valores setoriais apresentados na Tabela 1.

Inicialmente, para lançamento da planilha de custo industrial, os valores são previstos pelo setor de Engenharia de Processos, o qual o faz baseado em tempos similares. Posteriormente, para controle e melhoria, há a necessidade de se analisar os dados reais, sendo que a Figura 1, explanada com maior detalhamento por Orsini (2010), demonstra como tabular os dados para balanceamento da operação, indicando as operações do processo, os tempos coletados por cronoanálise no processo, a necessidade e o ajuste do número de operadores de acordo com a produção desejada e o cálculo do custo da mão de obra direta para esta configuração específica produtiva. Após o controle em separado da mão de obra direta, cabe agora alocar os funcionários indiretos no custo do produto, surgindo, para isto, a necessidade de rateio por algum tipo de método. O mais comum e utilizado neste objeto de estudo é o de absorção, onde se somam os 
salários e os dividem pela produção total da estimativa de custo a ser também controlada empresa no período, resultando em uma posteriormente por averiguação simples.

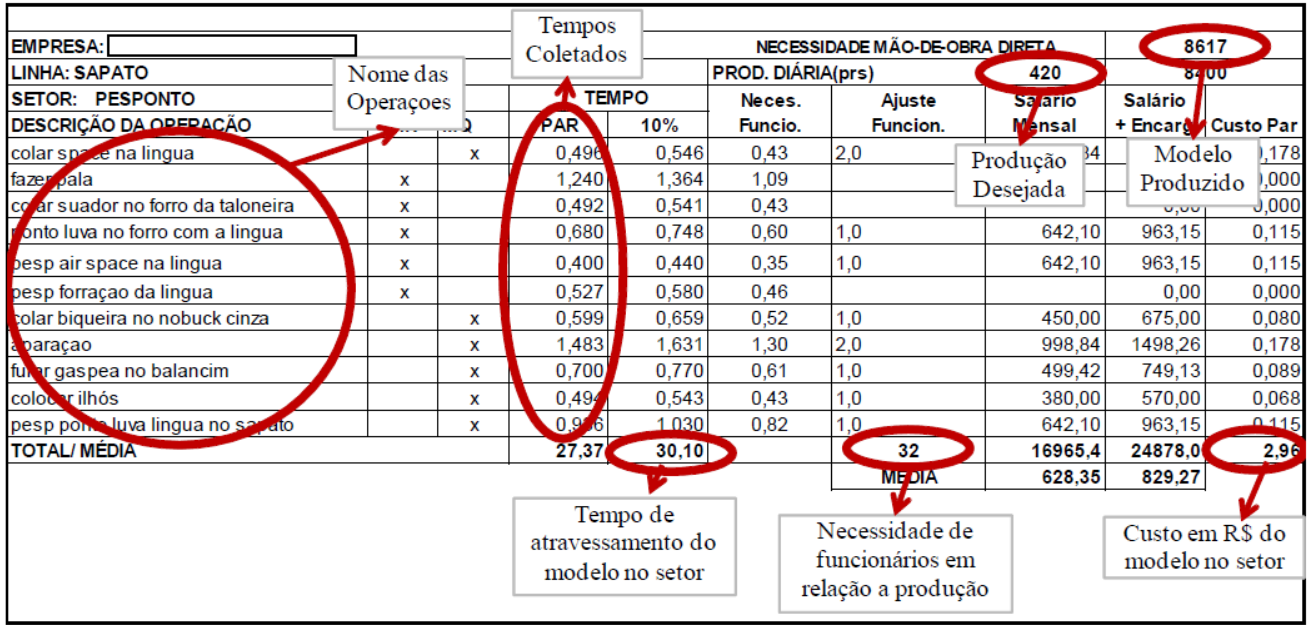

Figura 1 - Planilha de Cronoanálise e custos de linhas produtivas Fonte: ORSINI, 2010, p. 37.

Com isto, a célula ilustrada na figura 1 sobre a mão de obra no quesito Produção será dada pelos funcionários diretos enquanto os outros itens serão por absorção de cada par produzido.

\subsubsection{Controle de investimentos e manutenção}

Para tal previsão e controle, a organização estudada moldou-se de forma semelhante ao controle de insumos, onde todos os gastos provenientes do período são somados e divididos pela produção do mesmo período. O resultado deve ser comparado com o esperado no custo industrial e, caso seja diferente, cabe aos gestores a análise do histórico e das ações tomadas no período para atualização dos custos ou redução dos gastos neste quesito para o próximo período.

\subsubsection{Controle dos impostos, encargos e lucros}

Tais dados, de impostos e encargos, por serem provenientes de legislações, são apenas monitorados e atualizados conforme variações governamentais. Já em relação ao lucro, pode ser inserido ou aferido de duas formas, dependendo da estratégia da empresa e das definições dos gestores:

- Uma primeira forma seria por meio de um percentual fixo, alterando o preço de venda de acordo com as variações impostas no custo industrial. Tende a ser complexo, pois a concorrência do mercado pode apresentar preços mais competitivos;
- A segunda seria a variação da margem de lucro para manutenção do preço de venda fixo, normalmente atrelado a contratos de fornecimentos preestabelecidos. A complexidade desde modelo se dá na questão de que, se a variação no custo industrial for para cima, o lucro tem de ser reduzido, o que pode gerar insatisfação por parte da empresa.

No objeto de estudo há as duas formas de inserção ou controle dos lucros, dependendo do produto em questão. No caso de inserção de um percentual fixo, deve-se atrelar tal valor ao mercado, visualizando concorrentes e clientes. No caso de controle da margem de contribuição por preço fixo, devem-se buscar formas de se manter lucros na empresa, reduzindo custos ou melhorando os setores.

\subsection{Coleta de dados - Inserção das informações nas planilhas}

Conforme informado durante a estruturação da planilha e dos controles, os dados iniciais para cada modelo são coletados de acordo com 0 setor responsável pelo desenvolvimento. Os quesitos de materiais de consumo e de insumos são informados pelo setor de desenvolvimento de produto (P\&D) enquanto os custos de mão de obra direta e dos setores já são de responsabilidade do setor de Engenharia de Processos. Informações sobre taxas e impostos são dadas pela administração, no setor contábil.

Diante da coleta inicial dos dados, tornase possível a inclusão das informações da estrutura apresentada na Tabela 1 , sendo que a 
Tabela 4 indica o custo industrial e o preço de venda para um produto em específico exemplificado aqui. A produção estipulada deste produto na empresa é de 16000 pares por mês, gerada pela previsão de vendas do setor responsável.

Diante da Tabela 4, cabe agora melhorar os custos do produto, por meio da gestão da produção. Utilizando os controles apresentados no Tópico 4.3, cada item estratificado pode ser revisto e alterado, sempre com o intuito de condizer à experiência produtiva real com a planilha de dados, mantendo a acurácia dos dados virtuais. .

Tabela 4 - Custo industrial e Preço de Venda

\begin{tabular}{|c|c|c|c|c|c|c|c|}
\hline \multicolumn{8}{|c|}{ Custo industrial } \\
\hline Modelo & $8585 / 9-500$ & & Cliente & \multicolumn{4}{|c|}{$\mathrm{XXXX}$} \\
\hline \multicolumn{8}{|c|}{ Matérias-Primas } \\
\hline Cód & Descrição & Unid & Consumo unitário & \multicolumn{2}{|c|}{ Preço de compra } & \multicolumn{2}{|c|}{ Custo unitário } \\
\hline 100.000 .001 & Raspa Relax S1 18/20mm & $\mathrm{m}^{2}$ & 0,1925 & $\mathrm{R} \$$ & 16,54 & $\mathrm{R} \$$ & 3,18 \\
\hline 100.000 .003 & Napa Relax 10/12mm & $\mathrm{m}^{2}$ & 0,0462 & $\mathrm{R} \$$ & 22,05 & $\mathrm{R} \$$ & 1,02 \\
\hline 103.005 .005 & Forro Stroflex ar 1533 & $\mathrm{~m}^{2}$ & 0,0748 & $\mathrm{R} \$$ & 3,20 & $\mathrm{R} \$$ & 0,24 \\
\hline 104.003 .007 & Espuma PU 10mm & $\mathrm{m}^{2}$ & 0,0242 & $\mathrm{R} \$$ & 3,68 & $\mathrm{R} \$$ & 0,09 \\
\hline 102.001 .025 & Forro suador Stroflex 2505 & $\mathrm{~m}^{2}$ & 0,0220 & $\mathrm{R} \$$ & 4,54 & $\mathrm{R} \$$ & 0,10 \\
\hline 110.001 .013 & Ilhós ferro ouro velho & pç & 20 & $\mathrm{R} \$$ & 0,01 & $\mathrm{R} \$$ & 0,14 \\
\hline 103.002 .004 & Contraforte 8585 & $\mathrm{pr}$ & 1 & $\mathrm{R} \$$ & 0,13 & $\mathrm{R} \$$ & 0,13 \\
\hline 108.001 .012 & Palmilha conforto EVA & $\mathrm{pr}$ & 1 & $\mathrm{R} \$$ & 4,33 & $\mathrm{R} \$$ & 4,33 \\
\hline 115.001 .002 & Solado NSA MSM & $\mathrm{pr}$ & 1 & $\mathrm{R} \$$ & 5,55 & $\mathrm{R} \$$ & 5,55 \\
\hline 107.003 .015 & Atacador redondo preto $120 \mathrm{~mm}$ & $\mathrm{pr}$ & 1 & $\mathrm{R} \$$ & 0,22 & $\mathrm{R} \$$ & 0,22 \\
\hline & \multicolumn{5}{|c|}{ Custo total de matérias-primas } & \multicolumn{2}{|c|}{ R\$ 15,00 } \\
\hline \multicolumn{8}{|c|}{ Insumos } \\
\hline Cód & Descrição & Unid & Consumo período & \multicolumn{2}{|c|}{ Preço de compra } & & \\
\hline 125.001 .030 & Linha 30 preta & $\mathrm{kg}$ & 30 & $\mathrm{R} \$$ & 35,25 & & \\
\hline 125.001 .040 & Linha 40 preta & $\mathrm{kg}$ & 15 & $\mathrm{R} \$$ & 35,25 & & \\
\hline 125.005 .040 & Linha 40 branca & $\mathrm{kg}$ & 20 & $\mathrm{R} \$$ & 35,25 & & \\
\hline 120.001 .001 & Cola SWT Amazonas & $\mathrm{kg}$ & 4 & $\mathrm{R} \$$ & 75,00 & & \\
\hline & & \multicolumn{4}{|c|}{ Quantidade pares produzidos } & \multicolumn{2}{|c|}{16000} \\
\hline & & \multicolumn{4}{|c|}{ Custo total de insumos } & $\mathbf{R} \$$ & 0,16 \\
\hline \multicolumn{2}{|r|}{ Mão de obra } & \multicolumn{4}{|c|}{ Investimentos/Manutenção } & & \\
\hline Setor & Valor por produto & & Descrição & \multicolumn{2}{|c|}{ Total } & & \\
\hline Administração & 0,85 & & Desp. Fixas & $\mathrm{R} \$$ & 0,85 & & \\
\hline Almoxarifado & 0,15 & & Frete & $\mathrm{R} \$$ & 0,30 & & \\
\hline Corte & 0,69 & & Investimento & $\mathrm{R} \$$ & 0,50 & & \\
\hline Preparação & 0,59 & & Manutenção & $\mathrm{R} \$$ & 0,25 & & \\
\hline Pesponto & 2,89 & & & & & & \\
\hline Montagem & 1,03 & & & & & & \\
\hline Acabamento & 0,95 & & & & & & \\
\hline Expedição & 0,13 & & & & & & \\
\hline $\mathrm{P} \& \mathrm{D}$ & 0,35 & & & & & & \\
\hline Engenharia & 0,35 & & & & & & \\
\hline Custo total & 7,98 & & Custo Total & $\mathbf{R S}$ & 1,90 & & \\
\hline \multicolumn{2}{|c|}{ Total do Custo industrial } & \multicolumn{4}{|c|}{25,04} & & \\
\hline \multicolumn{8}{|c|}{ Preço de Venda } \\
\hline \multicolumn{2}{|r|}{ Mark-up } & \multicolumn{4}{|c|}{ Preço de venda } & & \\
\hline Setor & Valor por produto & & & & & & \\
\hline ICMS & $12,00 \%$ & & RS & 43,5 & & & \\
\hline PIS & $9,25 \%$ & & & & & & \\
\hline ISS & & & & & & & \\
\hline IR & $3,25 \%$ & & & & & & \\
\hline Comissão & $5,00 \%$ & & & & & & \\
\hline Juros e Taxas & $3,00 \%$ & & & & & & \\
\hline Lucro & $10,00 \%$ & & & & & & \\
\hline Total & $42,50 \%$ & & & & & & \\
\hline MARKUP & $57,50 \%$ & & & & & & \\
\hline
\end{tabular}

Fonte: Elaborado pelo autor

\section{Análise dos dados - Resultados obtidos}

Conforme dito, por meio da estrutura de custos e controle dos mesmos, o objeto de estudo pode reestruturar todos os seus preços de venda. Também pode acompanhar, produto a produto e determinar se os parâmetros inseridos foram concretizados na empresa, mantendo e melhorando os procedimentos internos

A Tabela 5 aponta as melhorias obtidas no quesito mão de obra, após averiguações e melhorias de processos por foco nos parâmetros do custo industrial.

Para tanto, o estudo de tempos e métodos, com foco em balanceamento de linhas foi utilizado, conforme Orsini (2010) apresenta, 
moldando a linha produtiva e reduzindo os desperdícios de produção.

Também por estudo de tempos e métodos e reestruturação dos setores de apoio produtivo, os valores também foram modificados, gerando ao final, uma redução de mais de $10 \%$ no custo de mão de obra.

$\mathrm{Na}$ questão dos insumos e materiais diretos, a melhoria acabou por não apresentar grandes efeitos, pois o modelo de coleta de dados inicial, executado pelo P\&D já apresentava uma boa precisão. Mesmo assim os dados foram atualizados conforme experiência produtiva e geraram uma redução, no caso deste produto em estudo, de 5 centavos (4 centavos nos materiais diretos e 1 centavo nos insumos).

Sobre os itens de investimentos manutenção, os mesmo foram mantidos, já que ainda não se realizou nenhum trabalho específico para melhorá-los. Com relação aos impostos e encargos, não houve mudanças, em vista que a legislação exige tais itens a serem pagos nos âmbitos federal, estadual e municipal.

Tabela 5 - Resultado de mão de obra

\begin{tabular}{|c|c|c|c|c|}
\hline Setor & \multicolumn{2}{|c|}{ Início do estudo } & \multicolumn{2}{|c|}{ Final do estudo } \\
\hline Administração & $\mathrm{R} \$$ & 0,85 & $\mathrm{R} \$$ & 0,57 \\
\hline Almoxarifado & $\mathrm{R} \$$ & 0,15 & $\mathrm{R} \$$ & 0,10 \\
\hline Corte & $\mathrm{R} \$$ & 0,69 & $\mathrm{R} \$$ & 0,56 \\
\hline Preparação & $\mathrm{R} \$$ & 0,59 & $\mathrm{R} \$$ & 0,45 \\
\hline Pesponto & $\mathrm{R} \$$ & 2,89 & $\mathrm{R} \$$ & 2,32 \\
\hline Montagem & $\mathrm{R} \$$ & 1,03 & $\mathrm{R} \$$ & 1,05 \\
\hline Acabamento & $\mathrm{R} \$$ & 0,95 & $\mathrm{R} \$$ & 0,95 \\
\hline Expedição & $\mathrm{R} \$$ & 0,13 & $\mathrm{R} \$$ & 0,12 \\
\hline P\&D & R\$ & 0,35 & $\mathrm{R} \$$ & 0,45 \\
\hline Engenharia & $\mathrm{R} \$$ & 0,35 & $\mathrm{R} \$$ & 0,35 \\
\hline Custo total & \multicolumn{2}{|c|}{ R\$ 7,98 } & \multicolumn{2}{|c|}{$\mathrm{R} \$ \mathbf{6 , 9 2}$} \\
\hline
\end{tabular}

Fonte: Elaborado pelo autor

Tabela 6 - Custo industrial e Preço de Venda após melhorias

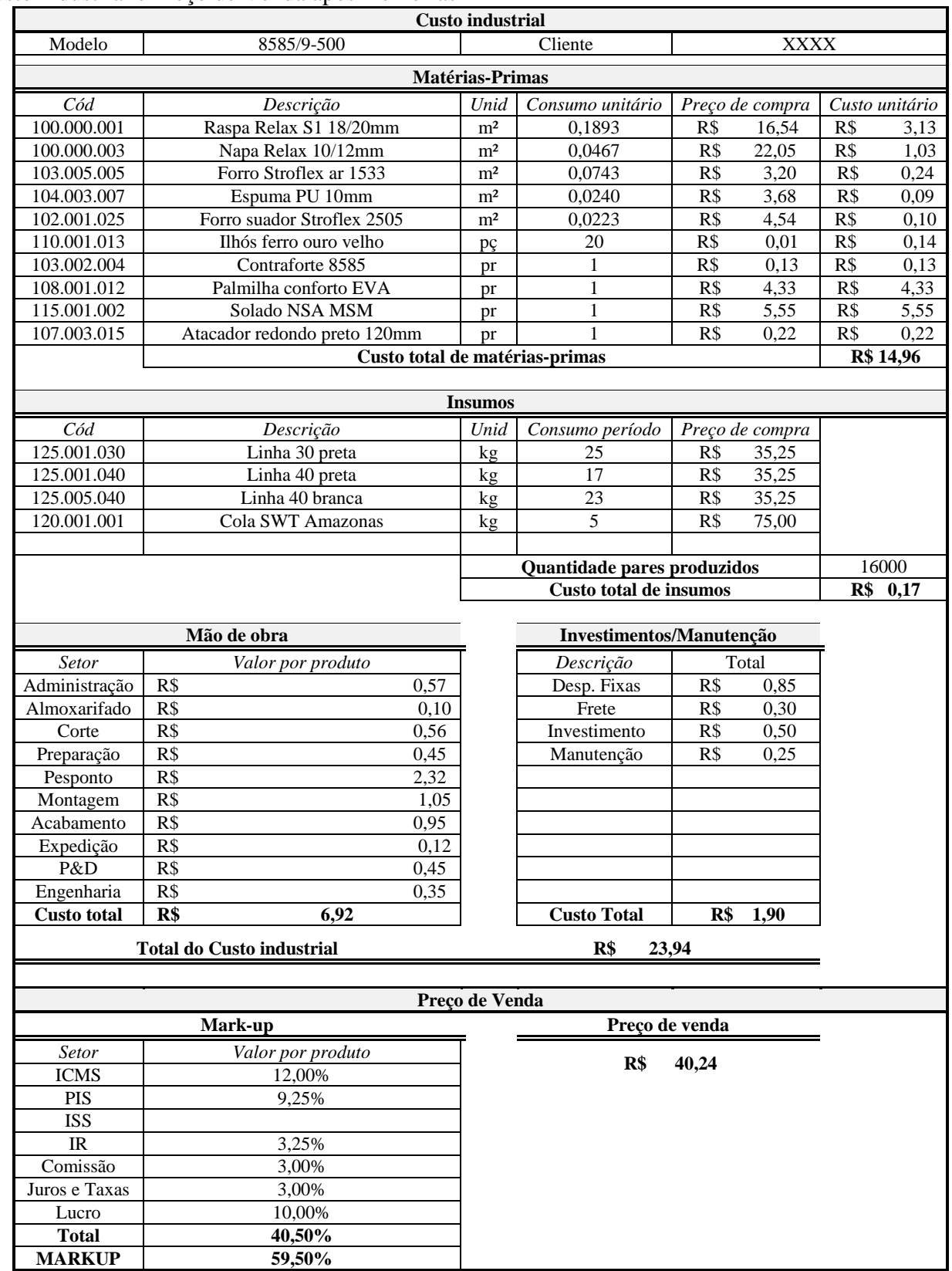

Fonte: Elaborado pelo autor 
Ao final das análises, constatou-se que o preço de venda teve uma redução significativa de quase 10\%, oferecendo melhor competitividade à firma. Os itens de controle de cada tópico da planilha trouxeram este reflexo de melhoria e continuam sendo visualizados diariamente com a finalidade ou de se manter os valores sem alterações ou de se buscar melhorias. A Tabela 6 apresenta a nova configuração de preços alcançada.

\section{Conclusões}

O custo industrial é um dos mais importantes parâmetros para as empresas e seus gestores. Ele representa o quanto custa fazer uma unidade de determinado produto, sem ter prejuízos, considerando todas as restrições do sistema e gerando o preço final de venda. Contudo, mesmo tendo tamanha importância, ainda há empresas que apenas se utilizam do know-how para determinar tais dados.

$\mathrm{Na}$ empresa objeto desta pesquisa, isso de fato ocorria e foi determinado um estudo mais aprofundado para reorganizar todo este sistema. Para tanto, elaborou-se em conjunto com a literatura a planilha para computar o custo industrial e o preço de venda dos produtos.

Também com estes dados foi possível obter melhorias diante de estudos de tempos e métodos baseados nos valores estruturados na planilha.

Diante disto, nota-se que os objetivos do trabalho foram conquistados, obtendo ao final a comparação da estrutura inicial para a empresa em um produto determinado com a nova formatação com as melhorias. Controlando e dando manutenção nos valores estruturados, houve a conquista de quase $10 \%$ de redução no preço de venda, resultando em maior competitividade para a empresa calçadista. Como o ramo de atuação deste tipo de empresas é extremamente competitivo, tal ganho representa muito para a indústria.

Durante a pesquisa houve dificuldades para a coleta dos dados em vista de que não havia dados corretos sobre produtos, mão de obra e outros da empresa, já que trabalhavam com a experiência e não com informações significativas.

Contudo, em vista dos prejuízos constantes na organização, houve o apoio total da alta administração para a revisão dos custos e do preço de venda e das melhorias organizacionais executadas.

Como contribuição científica, este trabalho é baseado em uma literatura já muito desenvolvida, contudo com aplicações diretas pouco observadas no ramo industrial de calçados. Uma planilha de custo industrial e preço de venda também não foi encontrada nos textos científicos, por isto a ferramenta também é um ganho para a teoria vigente.

Trabalhos futuros podem se utilizar desta modelagem para aplicação tanto no mesmo ramo calçadista como em novos ramos industriais, desde que considerando as mudanças necessárias para adequação aos novos setores.

\section{Referências Bibliográficas}

BETAGLIN, L. M. C.; BASÍLIO, T. L.; VIEIRA, J. G. V.; ROSSETI, N.. Avaliação de um arranjo físico e custos logísticos na transferência de maquinário em uma unidade fabril. Revista Eletrônica Produção \& Engenharia, v. 3, n. 2, p. 300-308, Jan/Jun, 2013.

CLEGG, S. R.; HARDY, C.; NORD, W. R. Handbook de Estudos Organizacionais - ação e análise organizacionais. Volume 3. São Paulo: Atlas, 1998.

COHEN, S.; KAIMENAKI, E. Costs accounting systems structure and information quality properties: an empirical analysis. Journal of applied accounting research, v. 12, n. 1, p. 5-25, 2011.

COLMANETTI, M. S. Modelagem de sistemas de manufatura orientada pelo custeio das atividades e processos. Dissertação (Mestrado) Engenharia Mecânica, USP, São Carlos, 2001.

COOPER, R.; KAPLAN, R. S. Measure costs right: make the right decisions. Harvard Business Review, p. 96-103, Sep/Oct 1988.

CORREIA NETO, J. F. Excel para profissionais de finanças - Manual Prático. Rio de Janeiro: Elsevier, 2007.

GODINHO FILHO, M.; FERNANDES, F. C. F.; LIMA, A. D. Pesquisa em Gestão da produção na indústria de calçados: revisão, classificação e análise. Revista Gestão e Produção, v. 6, n. 2, p. 163-186, 2009.

LAURINDO, F. J. B.; MESQUITA, M. A. Material Requirements Planning: 25 anos de história - uma revisão do passado e prospeç̧ão do futuro. Revista Gestão e Produção, v. 7, n. 3, p. 320-337, Dez. 2000.

LEE, B.; BOWHILL, B. Accounting for manufacturing: identifying the link between market, production and costing systems. Engineering Management Journal, Aug 1997.

MASSING, J. Planilha Eletrônica de Fluxo de Caixa. Trabalho de Conclusão de Curso (Graduação), Administração de Empresas, Universidade Luterana do Brasil, Santa Maria, 2006.

MARTINS, E. Contabilidade de custos. 10. Ed. São Paulo: Atlas, 2010.

MIGUEL, P. A. C.; FLEURY, A.; MELLO, C. H. P.; NAKANO, D. N.; TURRIONI, J. B.; LEE HO, L.; MORABITO, R.; MARTINS, R. A.; PUREZA, V. Metodologia de pesquisa em engenharia de produção $\mathrm{e}$ gestão de operações. Rio de Janeiro: Elsevier, 2010.

NAZARENO, R. R.; RENTES, A. F.; SILVA, A. L. Implantando técnicas e conceitos da produção enxuta integradas à dimensão de análise de custos. In: ENCONTRO NACIONAL DE ENGENHARIA DE 
PRODUÇÃO, 21, 2001, Salvador. Anais do XXI ENEGEP 2001.

ORSINI, F. E. Análise da mudança do arranjo físico de uma empresa de calçados de segurança. Trabalho de Conclusão de Curso (Graduação), Engenharia de Produção, Universidade de Franca, Franca/SP, 2010.

RAPOSO, C. F. C. Overall Equipment Effectiveness: aplicação em uma empresa do setor de bebidas do pólo industrial de Manaus. Revista Produção Online, v. 11, n. 3, p. 648-667, jul/set 2011.

SHEHAB, E. M.; ABDALLA, H. S. Manufacturing costs modeling for current product development. Robotics and computer integrated manufacturing, n. 17, p. 341-353, 2001.

SHINGO, S.. O sistema Toyota de produção - do ponto de vista da engenharia de produção. Porto Alegre: Bookman, 1996

SILVA, A. R. Y. Modelagem de custos em sistemas de manufatura utilizando redes de petri. Dissertação (Mestrado), Engenharia de Produção, USP, São Carlos/SP, 2002.

SLACK, N.; CHAMBERS, S.; JOHNSTON, R. Administração da Produção. 3. Ed. São Paulo: Atlas, 2009.

SOUZA, A. A.; NOVELI, M.; MINELLO, I. F.; ENDRILI, J. O. M.; AVELAR, E. A. Análise de sistemas de informações utilizados como suporte para os processos de estimação de custos e formação de preços. ABCustos Associação Brasileira de Custos, v. 1, n. 1, set/dez 2006.

TORRES JÚNIOR, N.; MIYAKE, D. I. Melhoria de desempenho em serviços: alternativas para lidar com o trade-off entre eficiência e eficácia. Revista Produção Online, v.11, n. 1, mar 2011.

VOLLMANN, T. E.; BERRY, W. L.; WHYBARK, D. C.; JACOBS, F. R. Sistemas de Planejamento e controle de produção para o gerenciamento da cadeia de suprimentos. 5. Ed. Porto Alegre: Bookman, 2006.

VOSS, C.; TSIKRIKTSIS, N.; FROHLICH, M. Case research in operations management. International Journal of Operation e Production management, v. 22, n. 2, p. 195-219, 2002.

WALKENBACH, J. Microsoft Excel ${ }^{\circledR} 2013$ - Power Programming with VBA. New Jersey: John Wiley \& Sons, 2013.

YIN, R. K. Estudo de caso - Planejamento e métodos. 3. Ed. Porto Alegre: Bookman, 2005. 